\section{Commentary: Cut to the chase: It's a matter of principle}

\author{
Matthew A. Romano, MD
}

It is well known that mitral valve repair is the gold standard therapy for patients with severe mitral regurgitation with degenerative valve disease that meet an indication for surgery. It can be performed with low mortality, it is durable, and carries a survival benefit. ${ }^{1}$ However, in North America only $40 \%$ to $60 \%$ of degenerative mitral valves are repaired, although this number does increase to $>95 \%$ in reference centers. Most degenerative mitral valve repair is for posterior leaflet pathology and the vast majority is for middle scallop prolapse. ${ }^{2-4}$ Numerous repair techniques, nonresectional and resectional, exist and have evolved over time. Often they have become more "simplified" with a goal to benefit patients by improving repair rates.

In this issue of JTCVS Techniques, Burns and colleagues ${ }^{5}$ present an elegant technique summary on targeted triangular resection to repair degenerative mitral regurgitation, which has shown effectiveness and durability. They clearly detail their method to obtain a competent repaired valve and highlight crucial nuances, such as timing of annular suture placement and the depth of resection in relation to the width of the triangle base. Equally important is that several valuable tips are illustrated to help the surgeon avoid potential pitfalls such as systolic anterior motion. As the authors acknowledge, it is important to realize that the techniques discussed are aimed at relatively straightforward, singlesegment pathology, and the caution is to not fall victim to a one size fits all approach. Furthermore, the techniques to repair the valve are numerous and one would be remiss

\footnotetext{
From the Department of Cardiac Surgery, University of Michigan, Ann Arbor, Mich. Disclosures: The author reported no conflicts of interest.

The Journal policy requires editors and reviewers to disclose conflicts of interest and to decline handling or reviewing manuscripts for which they may have a conflict of interest. The editors and reviewers of this article have no conflicts of interest.

Received for publication Oct 16, 2021; revisions received Oct 16, 2021; accepted for publication Oct 19, 2021; available ahead of print Oct 26, 2021.

Address for reprints: Matthew A. Romano, MD, Department of Cardiac Surgery, 5162 Frankel Cardiovascular Center, University of Michigan, 1500 E Medical Center Dr, Ann Arbor, MI 48109-5864 (E-mail: maromano@med.umich.edu). JTCVS Techniques 2021;10:53-4

2666-2507

Copyright (c) 2021 The Author(s). Published by Elsevier Inc. on behalf of The American Association for Thoracic Surgery. This is an open access article under the CC BY-NC-ND license (http://creativecommons.org/licenses/by-nc-nd/4.0/).

https://doi.org/10.1016/j.xjtc.2021.10.038
}

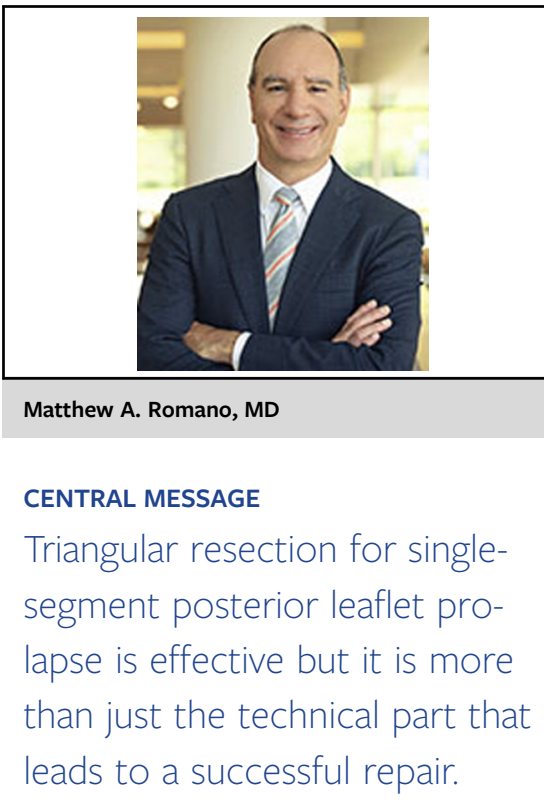

to not mention the contribution of nonresectional techniques. Although it is not the focus of this report, as the complexity of the lesions increase and involve multiple segments, commissures, annular calcification, and the like, the technical challenges of the repair increase as well as the need for adjunctive procedures. Ultimately the adroit surgeon will be required to develop a broad skill set to tackle degenerative mitral valve disease. What is laudable is the realization that the authors show that the ultimate importance of the underlying principle of a systematic approach that leads to a successful repair, and this is germane to any mitral valve repair, regardless of complexity. It commences with a clear understanding of the valve abnormality, leaflet motion, and the nature and location of the regurgitant jet, and this starts with careful study of the transesophageal echo, which can be easily overlooked. Often at this point the surgeon might already begin to map out a repair strategy and anticipate potential challenges and plan accordingly. This can be evidenced in the scenario of a long posterior leaflet and narrow left ventricular outflow tract with a septum to coaptation distance and narrow aorto-mitral angle and the risk of post-repair systolic anterior motion. Visualization is paramount and appropriate exposure is half the battle to a successful repair and therefore the surgeon should make every effort to optimize it. The repairs shown by the authors also highlight the need for a careful examination of the valve with a comprehensive understanding of the abnormal and normal components. Furthermore, it is the 
ability to visualize what the post repair valve will look like and the technical judgement to tailor the reconstruction, such as ensuring a posterior positioned zone of coaptation of appropriate length that leads to an effective and durable result.

The authors should be commended for their efforts to advance the understanding of the segmental triangular resection for posterior leaflet prolapse and aid the surgeons' level of comprehension and skill to repair mitral valve prolapse and increase repair rates. It is important to realize that the matter of principle is more than just where or how much to cut but rather it is the whole approach from start to finish that results in a successful repair.

\section{References}

1. David TE, Armstrong S, Ivanov J. Chordal replacement with polytetrafluoroethylene sutures for mitral valve repair: a 25 -year experience. J Thorac Cardiovasc Surg. 2013;145:1563-9. https://doi.org/10.1016/j.jtcvs.2012.05.030

2. Savage EB, Ferguson TB Jr, DiSesa VJ. Use of mitral valve repair: analysis of contemporary United States experience reported to the Society of Thoracic Surgeons National Cardiac database. Ann Thorac Surg. 2003;75:820-5.

3. Castillo JG, Anyanwu AC, Fuster V, Adams DH. A near $100 \%$ repair rate for mitral valve prolapse is achievable in a reference center: implications for future guidelines. J Thorac Cardiovasc Surg. 2012;144:308-12. https://doi.org/10.1016/ j.jtcvs.2011.12.054

4. Suri RM, Schaff HV, Dearani JA, Sundt TM III, Daly RC, Mullany CJ, et al. Survival advantage and improved durability of mitral repair for leaflet prolapse subsets in the current era. Ann Thorac Surg. 2006;82:819-26. https://doi.org/ 10.1016/j.athoracsur.2006.03.091

5. Burns DJP, Suri RM, Gillinov AM. Targeted triangular resection for repair of degenerative mitral valve disease. J Thorac Cardiovasc Surg Tech. 2021;10:47-52. 